\title{
Thermal Performance of MR-16 Light Emitting Diode Products
}

\author{
Michael Beck, Heather Dillon*, Belinda Li \\ Department of Mechanical Engineering, University of Portland, Portland, USA \\ Email: ${ }^{\text {dillon@up.edu }}$
}

How to cite this paper: Beck, M., Dillon, $\mathrm{H}$. and Li, B. (2016) Thermal Performance of MR-16 Light Emitting Diode Products. Journal of Electronics Cooling and Thermal Control, 6, 127-138.

http://dx.doi.org/10.4236/jectc.2016.64012

Received: September 3, 2016

Accepted: October 8, 2016

Published: October 11, 2016

Copyright $\odot 2016$ by authors and Scientific Research Publishing Inc. This work is licensed under the Creative Commons Attribution International License (CC BY 4.0).

http://creativecommons.org/licenses/by/4.0/

\begin{abstract}
The thermal properties of Light Emitting Diode (LED) products have a significant impact on their longevity and overall performance. Products which are unable to adequately dissipate heat degrade, shortening the projected lifespan. A testing apparatus has been constructed to characterize the thermal behavior of MR-16 LED products. This paper documents the testing setup and measurement results for 9 separate products, and identifies product characteristics which demonstrate higher success at heat dissipation. The thermal performance was quantified using experimental data and heat transfer models. Calculations to quantify the magnitude of heat transferred through radiation and convection in each LED product were performed. Results indicate some of the products are better optimized to enhance convection heat transfer.
\end{abstract}

\section{Keywords}

Heat Transfer, LED, MR-16, Convection, Radiation, Thermal Performance, Lighting

\section{Introduction}

Light Emitting Diode (LED) products offer significant advantages over incandescent and compact fluorescent lighting (CFL). LEDs boast a lifespan roughly three times longer than that of CFLs, and it is estimated that full market penetration of LEDs into the consumer light market would reduce greenhouse gas emissions from lighting by $46 \%$ [1].

Despite their promise thermal management is a common issue in current LED bulbs, a US Department of Energy study determined that many consumer products overheat from use under normal operation conditions, causing LED components to perform poorly, and over time to degrade [2] [3]. This results in poor light quality in the short-term, and reduces the overall lifespan for the products. It is hard for manufacturers to combat this issue, as computational fluid dynamics (CFD) modeling for these 
problems is computationally taxing and expensive.

Research has been performed that focuses on the thermal management of A-19 style LED products [4]. These products typically utilize very large aluminum heat sinks to try and protect their LED components, which make the bulb more expensive and less environmentally friendly [5] [6]. Most existing research focused on the thermal performance of specific-application LEDs, such as headlights, or on the LED packaging [7] [8]. A few individual computational models have been developed for specific product applications [9] [10]. Chi et al. focused on modeling the interaction of the LED package with the product elements [9]. Bender et al. performed a CFD analysis to verify a thermal design model for general LED applications [10]. The prior work did not focus on thermal characteristics of a variety of existing MR-16 products. This paper provides insights about the relative heat transfer modes in different MR-16 products at the product level that has not been explored by prior work.

CFD analysis of forced air flow was performed by Maaspuro and Tuominen [11], but natural convection is considered more suited for LED applications due to the long operating conditions. While not commonly optimized in LED product design, natural convection heat transfer in small enclosures has been widely studied [12] [13]. Recent work with boundary conditions that may represent the air gap in an MR-16 fixture has shown that optimizing temperature profiles may improve the transition to turbulent flow even with small temperature differences [14] [15]. This paper is a first step by characterizing the magnitude of convection and radiation that occurs in MR-16 products.

Research into the thermal performance of MR-16 products provides a unique opportunity. Because of their size and fixtures, MR-16 research naturally lends itself to a worst-case scenario thermal analysis. MR-16s are too small for the large heat sinks used on the A-19 lighting products, and also tend to be fixed into confined spaces where air flow is limited. Manufacturers have created many styles of MR-16s that are focused on increasing thermal performance, however, most manufacturers measure the total heat dissipated as the difference between the total energy and light produced rather than exploring the different heat transfer mechanisms. The variety in products provided an opportunity to determine which products optimize heat transfer by natural convection through innovative heat exchangers and fins.

A recent study by the US Department of Energy reported that the number of MR-16 products using LEDs has actually fallen from 25\% to 7\% in 2016 [16]. The same report found that efficacy has improved at a much slower rate than other LED product types, making a study of thermal performance and work to improve heat transfer important. This paper describes a thermal testing and modeling method that may be adopted by product manufacturers to improve thermal performance of LED systems. This research also extends the thermal analysis of MR-16s by comparing the thermal performance of multiple products with different types of heat exchangers.

\section{Experimental Method}

Commercially available MR-16 products were purchased, with a focus on collecting 
bulbs with a variety of thermal management styles. The chosen products were then cataloged and the manufacturer's specifications were recorded including power, lumen output, wattage, and color temperature, as summarized in Table 1.

The variety of heat exchangers in the selected products is wide. Manufacturers selected plastic, metal, or composite materials and arranged them in a wide variety of geometries. Some of the heat exchangers appear complex to manufacturer, implying that additional cost savings may be possible with improvements to thermal management.

Infrared photos were taken of the products and used to determine locations for thermocouple placement as shown in Figure 1. Individual thermocouples were then welded and calibrated. OMEGA 101 Bond thermo-epoxy was used to attach thermocouples to the chosen locations for data collection, and the epoxy was left to cure for a minimum of 24 hours. The other end of the thermocouples was connected to a data acquisition system using LabVIEW (version 2015) to record temperature.

Testing was conducted under worst case scenario conditions within a modified commercial ceiling fixture for a minimum of three hours per bulb, recording one temperature reading every 10 seconds as shown in Figure 2. Once collected, the data was imported into a MATLAB program (version R2015a) where it was processed for graphical comparisons and steady state temperature analysis. The MR-16 thermocouples were attached in several general locations as shown in Figure 3 and Figure 4.

\section{Experimental Results}

The MR-16's typically reached a steady state temperature profile after about $30 \mathrm{mi}$ nutes, implying that long term usage risks degrading performance easily. A typical temperature history over time is shown in Figure 5.

Table 1. Summary of the MR-16 products selected for testing. Products representing a range of power and color temperature reported by manufacturers were selected.

\begin{tabular}{cccc}
\hline Product & Rated & Measured & Color \\
\hline Label & Wattage & Wattage & Temperature \\
\hline A & {$[\mathrm{W}]$} & {$[\mathrm{W}]$} & {$[\mathrm{K}]$} \\
\hline B & 7 & 6.3 & 5000 \\
C & 5 & 4.5 & 2700 \\
D & 5 & 5.0 & 3000 \\
E & 6.5 & 6.9 & 3000 \\
I & 5 & 4.7 & 2700 \\
J & 5 & 4.9 & - \\
L & 6 & 5.9 & 3000 \\
N & 7 & 6.6 & 2700 \\
& 5 & 4.4 & 5000
\end{tabular}




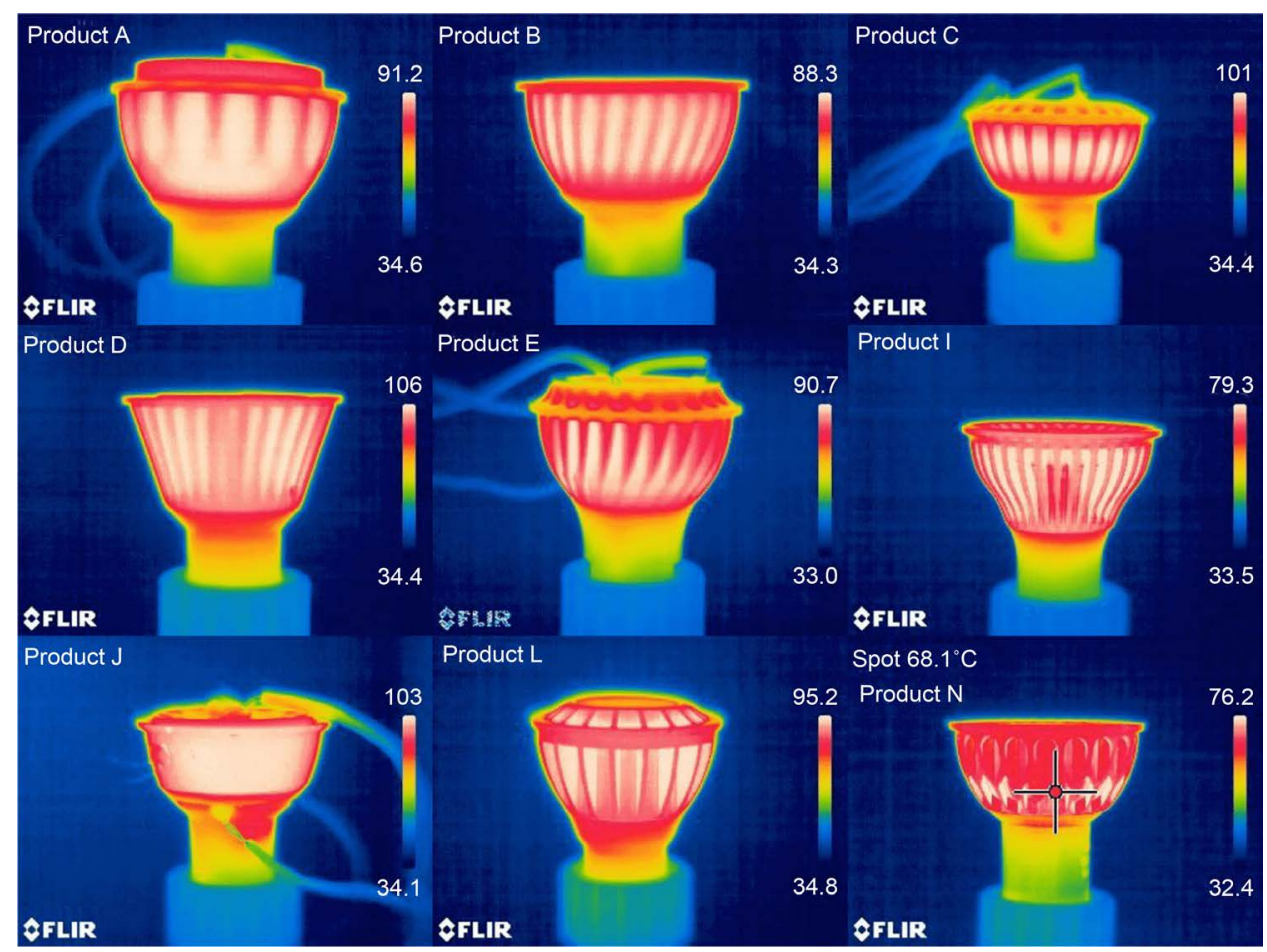

Figure 1. Infrared camera images of each product used for orientation and thermocouple placement.

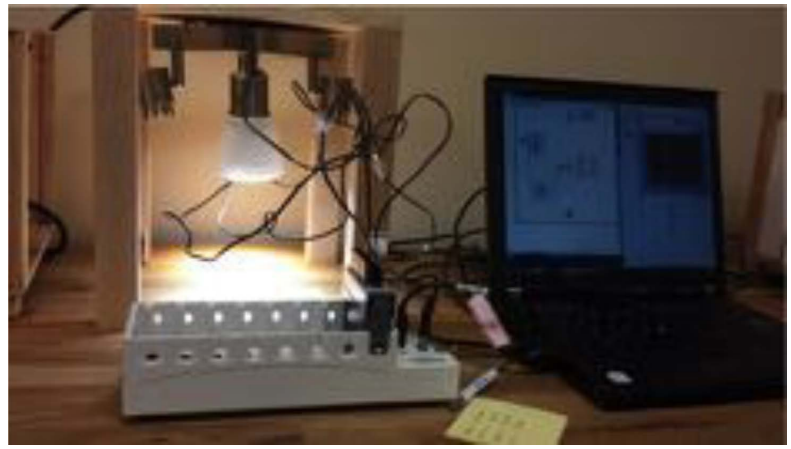

Figure 2. Thermal testing fixture for the study. The data acquisition system including the Labview system and laptop are shown.

For each product a more detailed steady state analysis of the temperature data was performed. An example of the steady state data is shown in Figure 6. The highest steady state temperature was achieved by MR-16 D and was over $100^{\circ} \mathrm{C}$, while the lowest temperatures came from MR-16 $\mathrm{N}$ at less than $65^{\circ} \mathrm{C}$. A summary of the temperature range by product is given in Figure 7. The infrared photos (Figure 1) reveal that while most of the product's hottest locations were their main bodies, the lowest temperature product had a cooler main body and very focused "hot spots" on the top edge and base that facilitated heat transfer.

Due to the steadiness of the ambient temperatures, the jagged steady state temperature behavior for MR-16 N (Figure 6) suggests that the heat exchanger design may be 


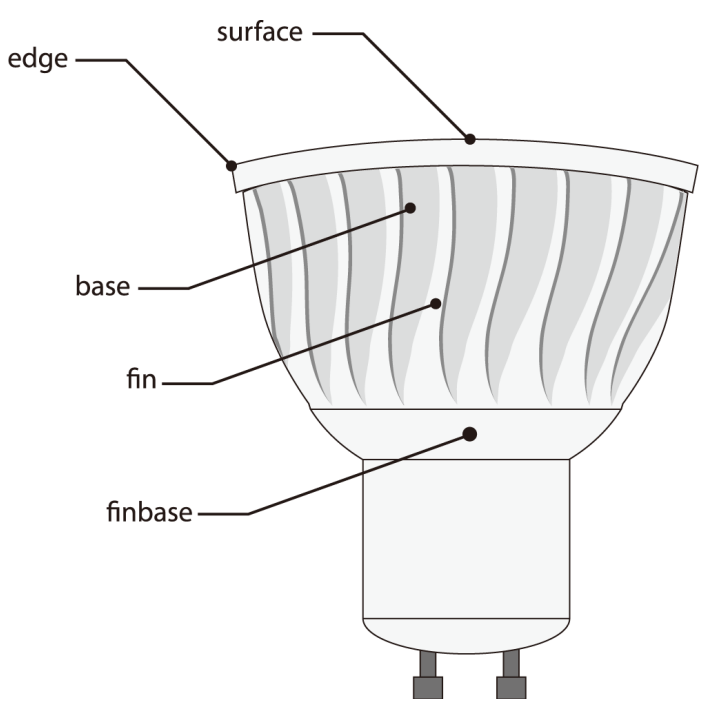

Figure 3. Naming convention and thermocouple location diagram for steady-state and transient temperature analysis for the LED product.

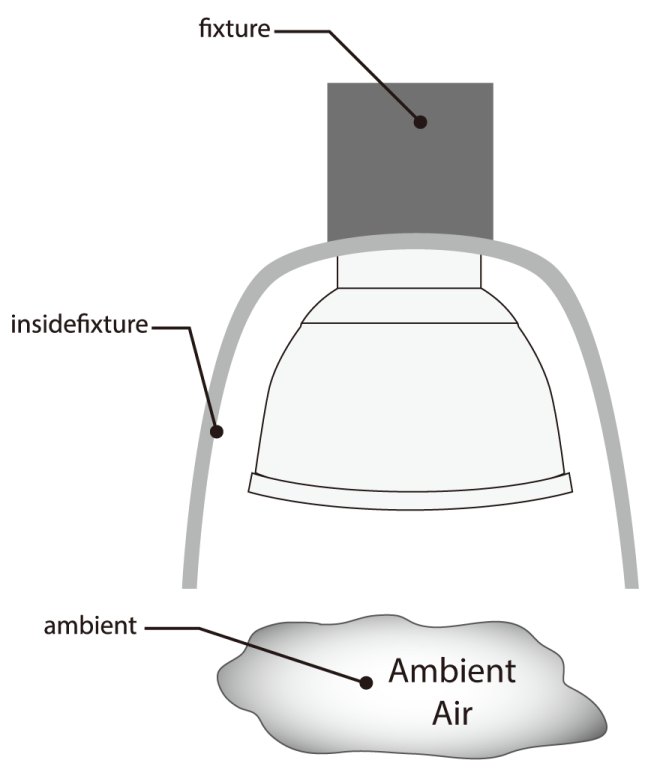

Figure 4. Naming convention and thermocouple location diagram for steady-state and transient temperature analysis for the lighting fixture and surroundings.

more effective at stimulating airflow, which in turn contributed to an overall cooler LED product system.

\section{Heat Transfer Model}

To model the heat transfer from each lighting product, the experimental temperature data was used to calculate rates of heat transfer due to both convection and radiation from the products.

The approach for the convection model was first to calculate the Rayleigh number $(R a)$. The Rayleigh number includes the fluid properties, in this case air, where $c_{p}$ is 


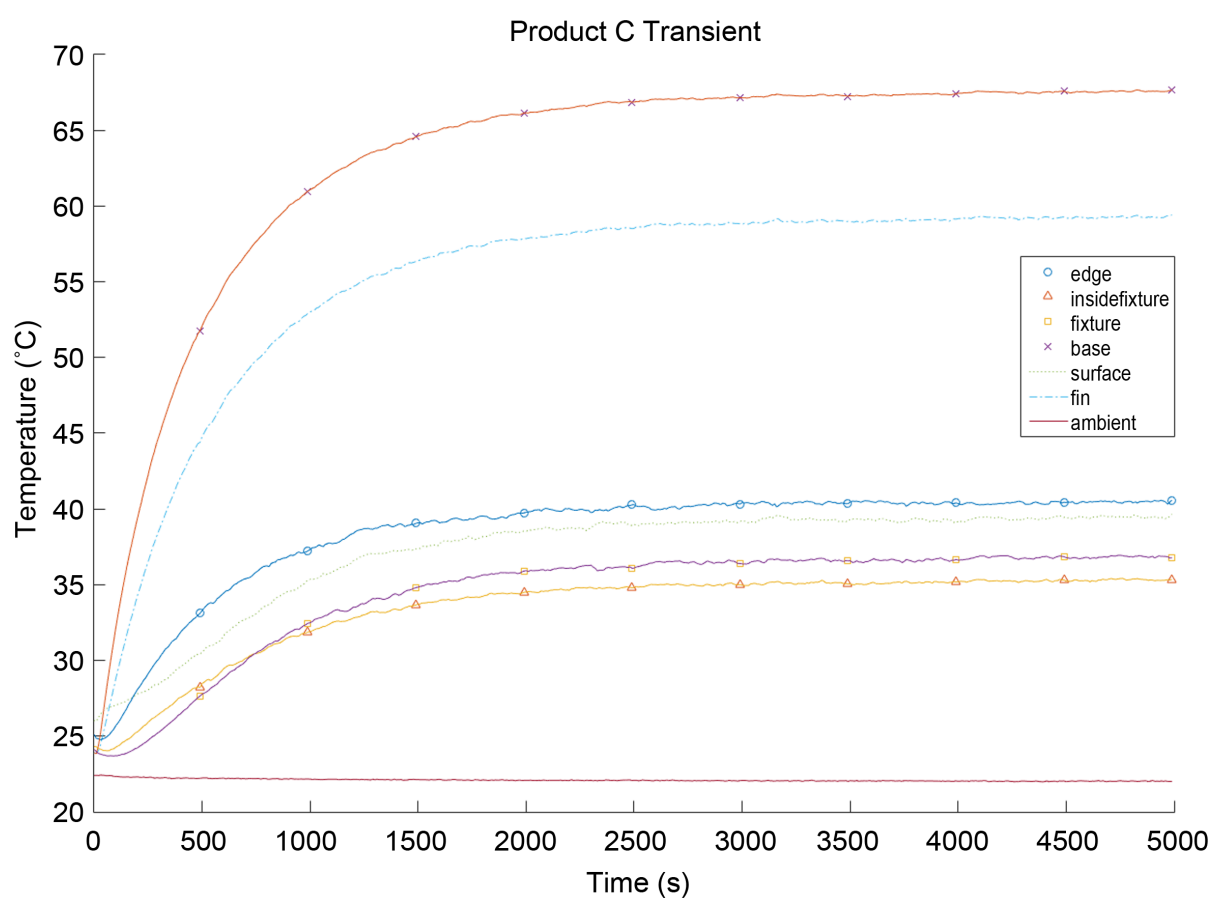

Figure 5. Example of a product temperature profile for MR-16 C. The product reaches a steady state temperature profile after 2500 seconds.

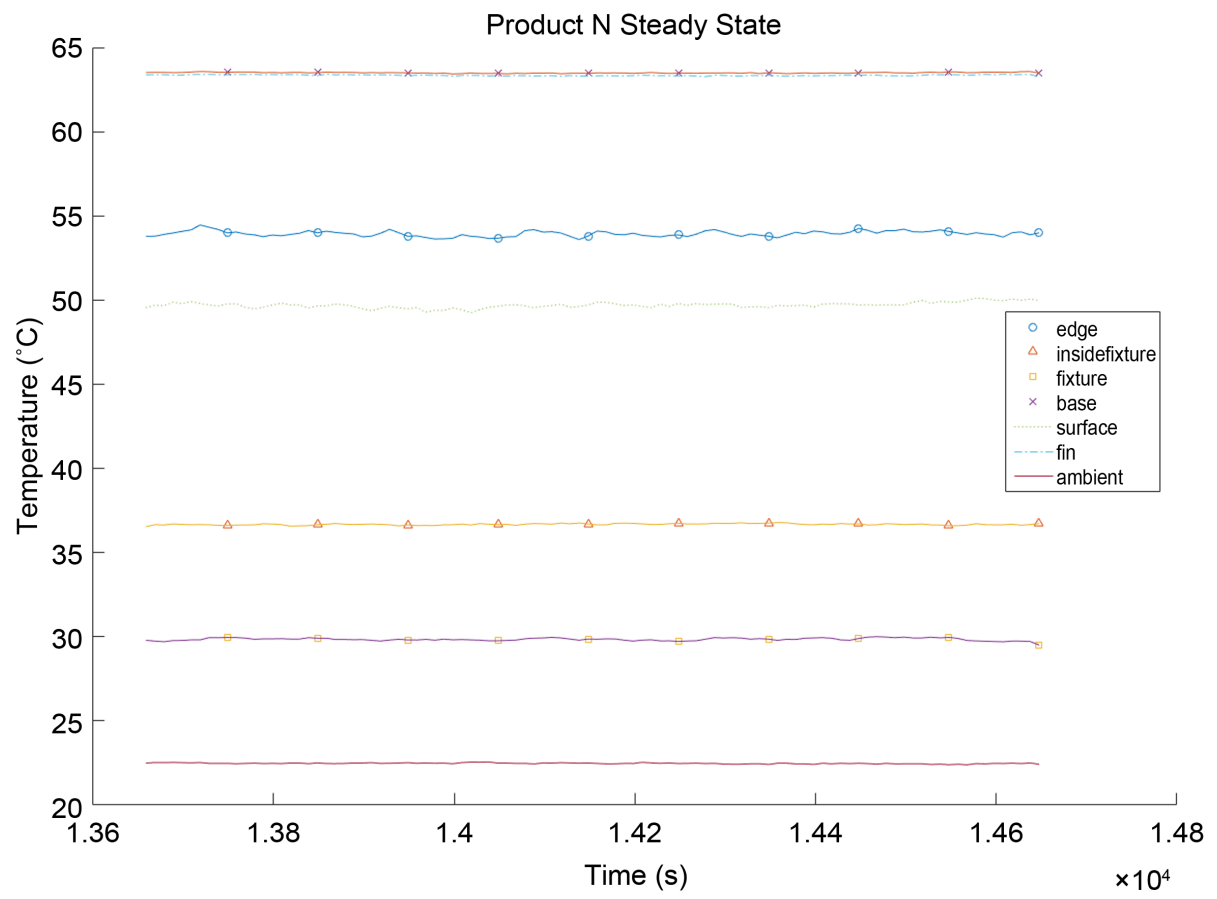

Figure 6. Example of the steady state product temperature profile for MR-16 N.

the specific heat at constant pressure; $\beta$ is the isobaric coefficient of thermal expansion; $\mu$ is the dynamic viscosity; $k$ is the thermal conductivity of the fluid; and $\rho$ is the density. The force of gravity $(g)$, the temperatures on the surface of the object $\left(T_{s}\right)$, 


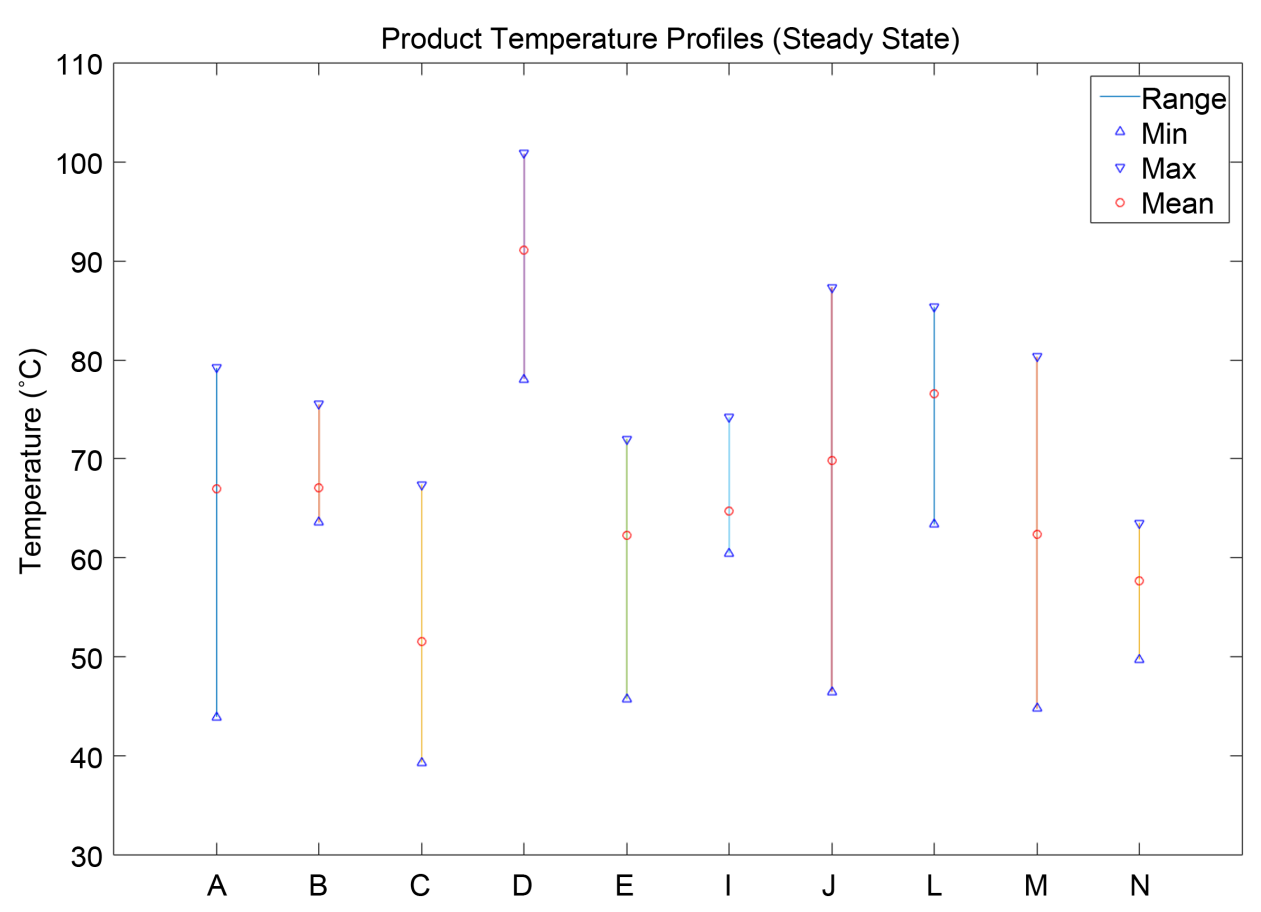

Figure 7. Product temperature profiles for all LEDs tested.

and the air $\left(T_{\infty}\right)$ are used for the calculation. A characteristic length $(L)$ was defined for each product using the methadology from Bergman et al. [17].

$$
R a_{L}=\frac{g \beta c_{p} \rho^{2}\left(T_{s}-T_{\infty}\right) L^{3}}{k \mu}
$$

The Rayleigh number was used to determine the Nusselt ( $\mathrm{Nu}$ ) number for different fluid behavior. The Nusselt correlations from Bergman et al. [17] were used for thermal property calculations based on the geometry and Rayleigh number for each product. For the flat exposed face of each MR-16 product the Nusselt correlation representing the lower face of a hot plate was used.

$$
N u_{L}=0.52 R a_{L}^{1 / 5}
$$

The convection from the vertical sides of the MR-16 products was approximated using the Nusselt correlation for flat vertical surfaces [17].

$$
N u_{L}=\left(0.825+\frac{0.387 R a_{L}^{1 / 6}}{\left[1+(0.492 / P r)^{9 / 16}\right]^{8 / 27}}\right)^{2}
$$

For this correlation, the Prandtl Number ( $P r)$ was calculated to characterize the fluid air.

$$
\operatorname{Pr}=\frac{c_{p} \mu}{k}
$$

Engineering Equation Solver (EES) was used to find thermophysical property lookups for air, to calculate thermal coefficients, and to perform surface area calculations 
for each product. The Nusselt number was used to calculate the heat transfer coefficient ( $h$ ) for each surface in the MR-16 products using the definition of the Nusselt number.

$$
N u_{L}=\frac{h L}{k}
$$

Once the heat transfer coefficient was determined for each surface, Newton's law of cooling was used to determine the heat transfer rate due to convection $\left(q_{\text {conv }}\right)$. The calculation used the experimentally measured temperatures of the air and surfaces and the calculated surface area $\left(A_{s}\right)$.

$$
q_{\text {conv }}=h A_{s}\left(T_{s}-T_{\infty}\right)
$$

The MR-16 products may also reject heat through thermal radiation. This was calculated using the Stefan-Boltzmann law. The surface emissivity $(\varepsilon)$ was estimated based on the type of material used and the temperature of the surrounding surfaces was approximated as $T_{\infty}$ or measured experimentally. The Stefan-Boltzmann constant has a fixed value, $\sigma=5.67 \times 10^{-8} \mathrm{~W} / \mathrm{m}^{2} \cdot \mathrm{K}^{4}$

$$
q_{\text {rad }}=\varepsilon \sigma A_{s}\left(T_{s}^{4}-T_{\infty}^{4}\right)
$$

The overall heat transfer model for a characteristic MR-16 product is shown in Figure 8. The calculated area values for each MR-16 product are shown in Table 2. For all the plastic fin materials the emissivity was estimated as $\varepsilon=0.91$ and for all the aluminum materials the emissivity was estimated as $\varepsilon=0.09$.

\section{Heat Transfer Model Results}

The calculated radiation and convection energy flow for each MR-16 product is summarized in Table 3. Results for product temperature ranges and heat transfer by radiation

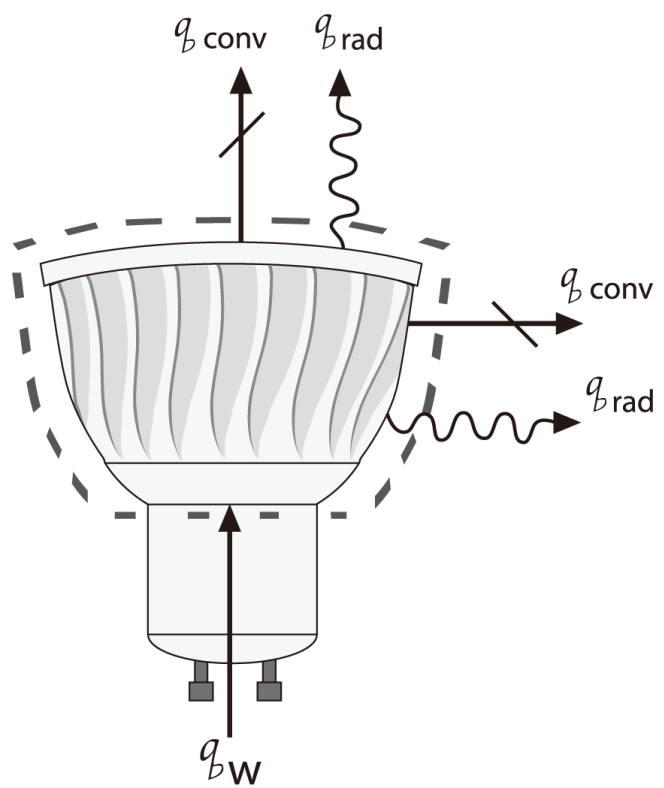

Figure 8. Model diagram representing energy flow in and out of the product in the form of electricity and heat. 
Table 2. MR-16 product thermal model areas.

\begin{tabular}{ccc}
\hline Product & Vertical & Face Surface \\
\hline Label & Surface Area & Area \\
\hline A & {$\left[\mathrm{m}^{2}\right]$} & {$\left[\mathrm{m}^{2}\right]$} \\
B & 0.001257 & 0.009823 \\
C & 0.001545 & 0.003965 \\
D & 0.001337 & 0.003881 \\
E & 0.001395 & 0.005113 \\
I & 0.001578 & 0.007449 \\
J & 0.001441 & 0.006293 \\
L & 0.001152 & 0.007555 \\
N & 0.001333 & 0.006278 \\
\hline
\end{tabular}

Table 3. Summary of the MR-16 product heat transfer modes.

\begin{tabular}{ccccccc}
\hline Product & Rated & Face & Body & Face & Body & Total \\
\hline Label & Power & Convection & Convection & Radiation & Radiation & Heat Transfer \\
\hline & {$[\mathrm{W}]$} & {$[\mathrm{W}]$} & {$[\mathrm{W}]$} & {$[\mathrm{W}]$} & {$[\mathrm{W}]$} & {$[\mathrm{W}]$} \\
\hline A & 7.0 & 0.163 & 1.261 & 0.163 & 2.331 & 3.918 \\
B & 5.0 & 0.420 & 0.573 & 0.430 & 0.817 & 2.240 \\
C & 5.0 & 0.130 & 0.542 & 0.134 & 0.759 & 1.565 \\
D & 6.5 & 0.537 & 1.098 & 0.543 & 1.698 & 3.876 \\
E & 5.0 & 0.369 & 0.702 & 0.378 & 0.978 & 2.427 \\
I & 5.0 & 0.354 & 0.998 & 0.354 & 1.564 & 3.270 \\
J & 6.0 & 0.309 & 1.238 & 0.296 & 2.085 & 3.927 \\
L & 7.0 & 0.357 & 1.567 & 0.354 & 0.214 & 2.493 \\
N & 5.0 & 0.229 & 0.904 & 0.231 & 1.173 & 2.537 \\
\hline
\end{tabular}

and convection for each product are shown in Figure 9. An ideal LED product would have low overall temperatures as defined by Figure 7 due to high performance LED components. However, an ideal product will also utilize the heat exchanger in an optimal way and maximize the heat transfer due to convection. If radiation heat transfer is the dominant mechanism for cooling, the heat exchanger may be removed or dramatically simplified since the fins are not contributing significantly to overall heat dissipation.

The results indicated that most of the products rejected 2 - 4 Watts of energy through both convection and radiation heat transfer. Some products, like MR-16 C had low overall heat transfer relative to the total rated wattage, but this was driven by the relatively low operating temperatures for the system. 


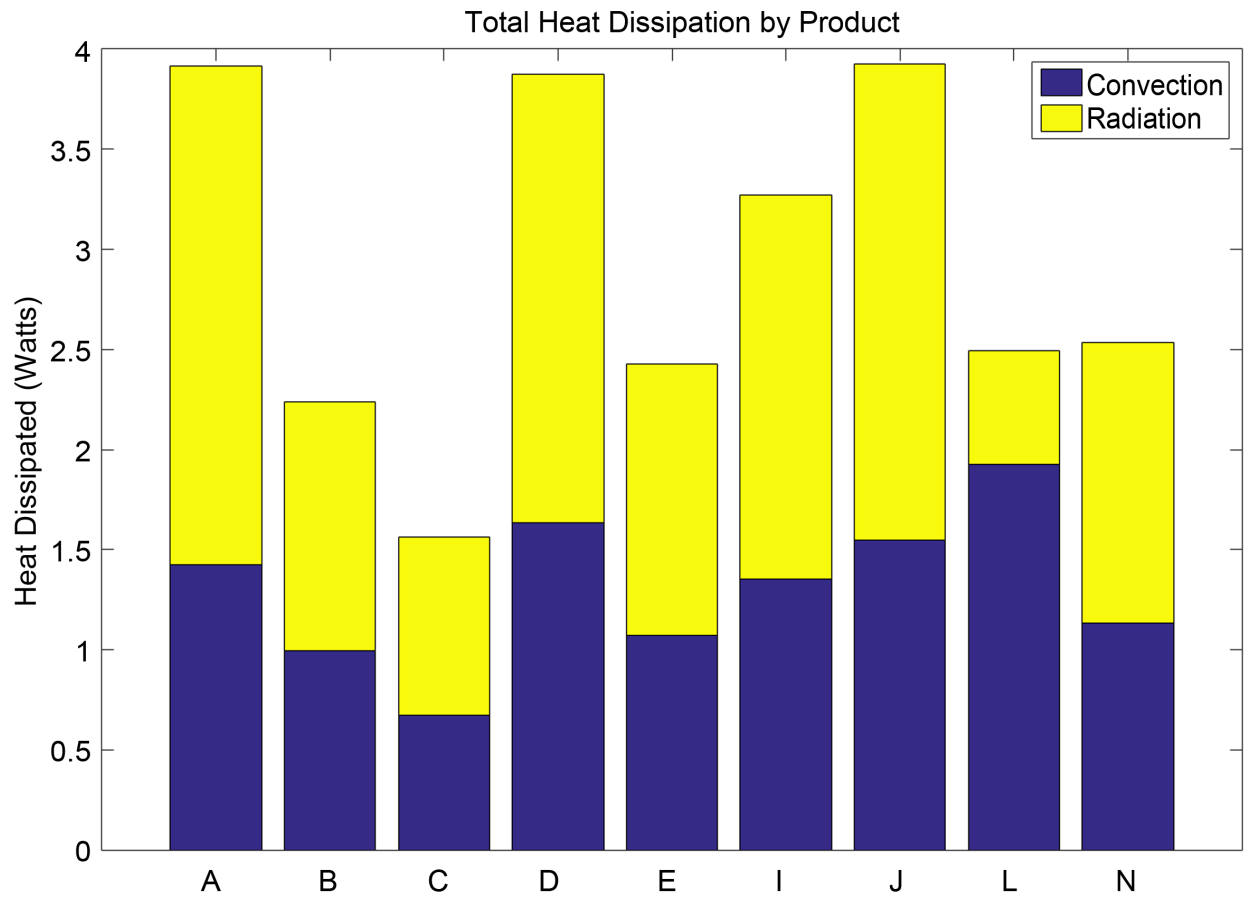

Figure 9. Summary of the relative contributions of radiation and convection to total heat transfer in each MR-16.

Since most of the products have relatively large heat exchangers that add significant weight and size to the MR-16, the products with low convection relative to radiation appear to be utilizing the large heat exchanger poorly. Examples include MR-16 A and MR-16 D that are both dominated by radiation heat transfer. This represents an opportunity for significant improvement in the product design. Since radiation heat transfer is a surface to surface mode of heat transfer, the manufacturer may be able to reduce the weight of the product or enhance convection with better optimization of the temperature profile in the heat exchanger fins.

Several of the products have relatively high convection heat transfer compared to radiation, indicating a preferred heat exchanger design. This category includes MR-16 $\mathrm{L}$, and the heat exchanger for this product is shown in Figure 10.

\section{Conclusions}

A set of experiments has been performed to document the thermal behavior of the emerging MR-16 LED products. MR-16 C and MR-16 $\mathrm{N}$ had the lowest overall temperatures under steady state conditions, averaging $50^{\circ} \mathrm{C}-60^{\circ} \mathrm{C}$ during testing in a fixture. Both of these products are designed to allow air flow between the fins and the exterior of the fixture as shown in Figure 10.

MR-16 L had the highest ratio of convection heat transfer. This is one of the few products tested to use metal in the heat exchanger, and has a relatively wide fin shape relative to other products (Figure 10). This implies that the additional cost of metal heat exchangers may improve heat transfer characteristics, particularly for higher temperature 


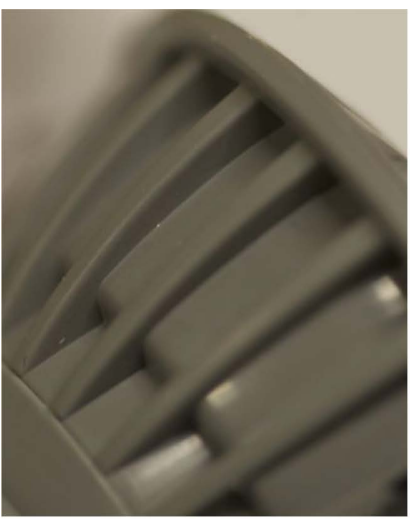

(a) Product $\mathrm{C}$

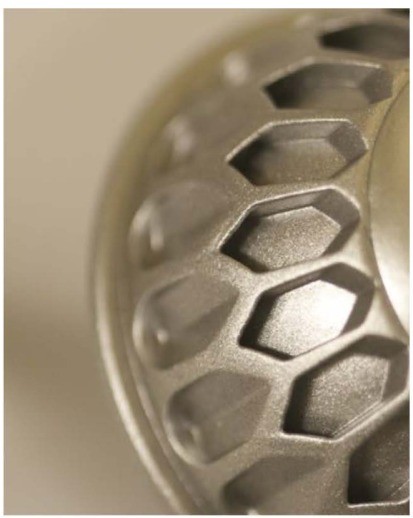

(b) Product N

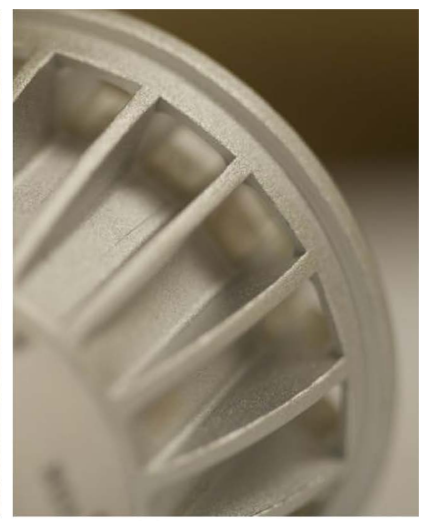

(c) Product L

Figure 10. Geometry and structure of heat exchanger fins for higher performance convection systems.

products. Product $\mathrm{N}$ has a non-traditional fin shape, but does seek to maximize the exposed surface area to the air flow (Figure 10). During steady state testing, both of these products exhibited signs of oscillatory behavior consistent with an increase in convection air flow.

Heat transfer modeling of the MR-16 products indicated many of the systems are reliant on radiation heat transfer when convection heat transfer could be optimized for each system. A thermal model has been developed and tested on several products that could be used to augment existing manufacturer LED thermal testing.

The experimental results indicate that for the temperature range experienced by most of the MR-16 products, natural convection could be optimized to become oscillatory or turbulent with small changes to product temperature profiles. This is the focus of future research, where the onset of turbulent air flow may be enhanced using known geometries [14] [15]. While time intensive, special CFD models may be used to further optimize heat exchanger design and placement in the MR-16 products.

\section{Acknowledgements}

Special thanks to Dean Jones and Shiley School of Engineering for partial funding of this research. Thanks to Saturday Academy for supporting the project and students working on it. Gratitude to Crysta Ross, Lydia Gingerich, and Justin Roberts for assisting with experimental work and setup. Thanks to Marc Ledbetter and the LED Lighting team at the Pacific Northwest National Laboratory for consultation and support.

\section{References}

[1] Navigant Consulting Inc. (2010) Energy Savings Potential of Solid-State Lighting in General Illumination Applications 2010 to 2030. Technical Report February, US Department of Energy.

[2] Pacific Northwest National Laboratory (2009) Thermal Management of White LEDs. Technical Report, US Department of Energy.

[3] Chi, W.-H. and Chiang, K.-N. (2010) Light Degradation Prediction of High-Power Light- 
Emitting Diode Lighting Modules. 11 th International Thermal, Mechanical \& Multi-Physics Simulation, and Experiments in Microelectronics and Microsystems (EuroSimE), Bordeaux, April 2010, 1-6.

[4] Storey, T.J., Rackerby, R.E., Dillon, H.E. and Gingerich, L. (2016) Thermal Performance of Domestic Replacement A19 LED Lighting Products. American Society of Mechanical Engineers International Mechanical Engineering Conference, Phoenix, 11-17 November 2016, IMECE2016-67974.

[5] Scholand, M.J. and Dillon, H.E. (2012) Life-Cycle Assessment of Energy and Environmental Impacts of LED Lighting Products. Part 2: LED Manufacturing and Performance. Technical Report, US DOE.

[6] Tähkämö, L. and Dillon, H.E. (2014) Handbook of Advanced Lighting Technology. Springer International Publishing, Cham.

[7] Cheng, T., Luo, X.B., Huang, S.Y. and Liu, S. (2010) Thermal Analysis and Optimization of Multiple LED Packaging Based on a General Analytical Solution. International Journal of Thermal Sciences, 49, 196-201. http://dx.doi.org/10.1016/j.ijthermalsci.2009.07.010

[8] Luo, X. and Liu, S. (2007) A Microjet Array Cooling System for Thermal Management of High-Brightness LEDs. IEEE Transactions on Advanced Packaging, 30, 475-484. http://dx.doi.org/10.1109/TADVP.2007.898522

[9] Chi, W.-H., Chou, T.-L., Han, C.-N., Yang, S.-Y. and Chiang, K.-N. (2010) Analysis of Thermal and Luminous Performance of MR-16 LED Lighting Module. IEEE Transactions on Components and Packaging Technologies, 33, 713-721.

http://dx.doi.org/10.1109/TCAPT.2010.2073469

[10] Bender, V.C., Iaronka, O. and Marchesan, T.B. (2013) Study on the Thermal Performance of LED Luminaire Using Finite Element Method. IECON2013: 39th Annual Conference of the IEEE Industrial Electronics Society, Vienna, November 2013, 6099-6104.

[11] Maaspuro, M. and Tuominen, A. (2013) Thermal Analysis of LED Spot Lighting Device Operating in External Natural or Forced Heat Convection. Microelectronics Reliability, 53, 428-434. http://dx.doi.org/10.1016/j.microrel.2012.10.004

[12] Lee, Y. and Korpela, S.A. (1983) Multicellular Natural Convection in a Vertical Slot. Journal of Fluid Mechanics, 126, 91-121. http://dx.doi.org/10.1017/S0022112083000063

[13] Chenoweth, D.R. and Paolucci, S. (1996) Natural Convection in an Enclosed Vertical Air Layer with Large Horizontal Temperature Differences. Journal of Fluid Mechanics, 169, 173-210. http://dx.doi.org/10.1017/S0022112086000587

[14] Dillon, H.E., Emery, A.F. and Mescher, A.M. (2013) Analysis of Chaotic Natural Convection in a Tall Rectangular Cavity with Non-Isothermal Walls. Frontiers in Heat and Mass Transfer (FHMT), 4, 1-9.

[15] Dillon, H.E., Emery, A.F. and Mescher, A.M. (2009) Benchmark Comparison of Natural Convection in a Tall Cavity. COMSOL User Conference, Boston, 8-10 October 2016, 1-10.

[16] PNNL (2016) CALiPER Snapshot MR16 Lamps. Technical Report.

[17] Bergman, T.L. and Incropera, F.P. (2011) Introduction to Heat Transfer. John Wiley \& Sons, Hoboken. 
Submit or recommend next manuscript to SCIRP and we will provide best service for you:

Accepting pre-submission inquiries through Email, Facebook, LinkedIn, Twitter, etc. A wide selection of journals (inclusive of 9 subjects, more than 200 journals)

Providing 24-hour high-quality service

User-friendly online submission system

Fair and swift peer-review system

Efficient typesetting and proofreading procedure

Display of the result of downloads and visits, as well as the number of cited articles

Maximum dissemination of your research work

Submit your manuscript at: http://papersubmission.scirp.org/

Or contact jectc@scirp.org 